\title{
PUBLICIDADE E ENTRETENIMENTO: transformações na relação entre comunicação, consumo e tecnologia
}

\author{
Beatriz Braga Bezerra ${ }^{1}$
}

Resumo: Vivemos a cultura do consumo, do espetáculo e das tecnologias. O entretenimento se coloca como linguagem fluida a percorrer os diversos campos e conteúdos da comunicação. Enquanto consumidores, demandamos ludicidade, diversão e prazer. E estamos sendo atendidos. Diante desse panorama, o artigo tem como objetivo investigar de que maneira a comunicação midiática - principalmente a publicidade - se apropria desse contexto para produzir seus discursos. Com os suportes teóricos de Don Slater (2002), Nicolau Sevcenko (2001), Muniz Sodré (2001; 2006), Arlindo Machado (2001) e outros, analisaremos, como culminância dessa investigação, a campanha publicitária do smartphone iPhone 6s da marca Apple - intitulada "Só mudou uma coisa. Tudo".

Palavras-chave: Comunicação e consumo; entretenimento; publicidade; tecnologia.

Abstract: We experienced the culture of consumption, spectacle and technology. Entertainment acts as fluent language to travel through the various spheres of communication. As consumers, we want playfulness, fun and pleasure. And we're getting it. That said, the article aims to investigate how media communication - especially advertising - appropriates this context to produce their speeches. With the theoretical support of Don Slater (2002), Nicolau Sevcenko (2001), Muniz Sodré (2001, 2006), Arlindo Machado (2001) and others, we will observe, as the culmination of this investigation, the advertising campaign "The only thing that's changed is everything" from Apple's iPhone 6s.

Keywords: Communication and consumption; entertainment; advertising; technology.

\section{Introdução}

"A redefinição das horas de folga como horas de consumo, a transformação do lazer em mercadoria, tem sido crucial na manutenção do crescimento capitalista", afirmou Don Slater (2002, p.36). O consumo e a ludicidade, então, caminham de mãos dadas na sociedade capitalista contemporânea. Vivemos a cultura do consumo. Nossos valores são permeados pelos ideais do consumo. Juntamente com o entretenimento, essa cultura nos impulsiona à efemeridade, à acumulação e substituição de bens, ao consumo de experiências.

Para Nicolau Sevcenko (2001, p.73), a indústria do entretenimento surgiu e se consolidou, com o suporte da eletricidade e dos avanços tecnológicos, fundada em "emoções baratas": atividades de baixo custo e grande alcance que divertiam a população com truques de ilusão e verdadeiras chacoalhadas nos corpos que buscavam alívio e um pouco de

${ }^{1}$ Doutoranda no Programa de Comunicação e Práticas do Consumo da Escola Superior de Propaganda e Marketing - ESPM e Bolsista Capes/Prosup. E-mail: beatriz.braga@hotmail.com. 
adrenalina. Na contemporaneidade, soma-se a esse cenário o enaltecimento da visualidade, do espetáculo e dos ambientes virtuais.

Diante disso, o trabalho tem como objetivo investigar de que forma a comunicação midiática - mais especificamente a publicidade - se apropria desse predomínio imagético, do culto ao consumo e da produção do espetáculo para construir seus discursos considerando também a inserção das tecnologias e do entretenimento no nosso cotidiano. Utilizaremos como aportes teóricos: Don Slater (2002) resgatando um pouco da teoria sobre a cultura de consumo; Muniz Sodré $(2006 ; 2001)$ ao defender o conceito de bios midiático que estamos envoltos atualmente; Everardo Rocha (2009) explicando o papel de atribuição simbólica exercido pelas narrativas midiáticas; Nicolau Sevcenko (2001) ao pontuar o trajeto histórico e as transformações comportamentais ocorridas como advento da eletricidade e da tecnologia na rotina das pessoas, bem como o surgimento das atividades de entretenimento propiciadas pela energia elétrica; Joyce Coelho e Vinícius Pereira (2008) argumentando sobre o espraiamento do entretenimento enquanto linguagem e Arlindo Machado (2001) ao contextualizar a relação "totêmica" que estabelecemos com os aparelhos eletrônicos de enunciação audiovisual. Como culminância desse percurso teórico, analisaremos a campanha publicitária do smartphone iPhone 6s da marca Apple - intitulada "Só mudou uma coisa. Tudo".

\section{Comunicação Midiática e Cultura do Consumo}

Sodré (2006, p.99) defende a perspectiva de que a comunicação midiática precisa ser compreendida, principalmente diante de suas reflexões sobre a televisão, como geradora de uma "forma de vida", de um "espaço social", de um "duplo exteriorizado" que finda por constituir a realidade. Para o autor (2001, p.21), com os meios de comunicação audiovisual e mais recentemente com a internet, "construiu-se um campo onde a representação não é mais do mesmo tipo da representação tradicional, ou seja, do universo da escrita. Agora a representação é apresentativa”. Ou seja, a comunicação midiática estabelece uma realidade de tamanha amplitude que nos envolve. Então ele define o conceito do que chama de bios midiático: 
que organizam a vida humana na cidade, vida humana sociabilizada, eu me dei conta de que existe um quarto bios hoje, trazido pelo mercado, pelo capitalismo transnacional, que é o bios-virtual, ou bios mediático. Isso significa uma outra esfera da existência, uma outra forma de vida (SODRÉ, 2001, p.24).

Dessa forma, Sodré (2006, p.102) percebe a mídia como uma "ambiência", uma "virtualidade" em que estamos imersos e o bios midiático, portanto, se estabelece como a “indistinção entre tela e realidade - realidade 'tradicional', bem entendido, uma vez que a realidade de hoje já se constitui sob a égide da integralidade espetacularizada ou imagística a que aspira o virtual”. A imagem e a exacerbação da estética se consolidam, atualmente, como determinantes da história regendo as relações sociais e propagando o culto ao espetáculo: "a espetacularização é, na prática, a vida transformada em sensação ou em entretenimento, com uma economia poderosa voltada para a produção e consumo de filmes, programas televisivos, música popular, parques temáticos, jogos eletrônicos", afirma o autor (SODRÉ, 2006, p.102).

Efeitos de fascinação, moda, celebridade e emoção a todo custo permeiam sistematicamente essa forma de vida emergente, em que a estesia detém o primado sobre velhos valores de natureza ética. $\mathrm{O}$ fenômeno estético torna-se insumo para a estimulação da vida, doravante dirigida para a indústria e o mercado (...). Na prática, porém, trata-se de um real semiurgicamente constituído em toda a sua extensão, uma verdadeira cultura das sensações e emoções, da qual se faz uma experiência mais afetiva do que lógico-argumentativa (...). Realiza-se uma espécie de 'ação estética' industrial, extensiva à vida social como um todo (SODRÉ, 2006, p.102).

A mídia, entendemos assim, expande a "realidade tradicional" e se agrega a ela, criando seu espaço de concorrência junto às demais instituições construtoras da consciência humana como a família e a escola, destaca Sodré (2001, p.20). A publicidade, por exemplo, realiza a função sensorial de envolvimento, "de paternalização, de garantir ao sujeito de que alguma coisa no nível macro, no nível do consumo, está velando por ele”; no entanto, diferentemente da educação de base em que formamos nossos princípios e valores, na mídia as regras a seguir têm cunho comercial: "a mídia tem uma moralidade mercantil, moralidade de vendedor, de comerciante" (SODRÉ, 2001, p.20).

Nos dias de hoje, juntamente com a realidade constituída pela comunicação midiática, vivemos a complexidade da cultura do consumo. Daniel Miller (2007, p.34) afirma que por muito tempo a compreensão e os textos escritos sobre o consumo o definiram como algo negativo e prejudicial à sociedade. Muitos teóricos refletiram sobre o consumo em seus 
estudos e o tomaram como sinônimo do "moderno consumo de massa", abandonando um possível "reconhecimento do quanto seu crescimento poderia também ser visto como sinônimo da abolição da pobreza ou do desejo por desenvolvimento", pontua Miller (2007, p.34).

Slater (2002, p.12) explica que se, por um lado, nossas "necessidades podem ser consideradas naturais e evidentes por si mesmas; por outro lado, são vistas muitas vezes como arbitrárias e subjetivas - como 'carências', 'caprichos', 'preferências' ou 'desejos' que dependem inteiramente das peculiaridades dos indivíduos". Nesse sentido, o autor defende que a cultura do consumo não pode ser pensada como algo "trivial", pois ela está profundamente entrelaçada com nossos cotidianos (SLATER, 2002, p.13).

\footnotetext{
No próprio processo de colaborar na constituição da vida privada, a cultura do consumo ligou inextrincavelmente o universo íntimo ao público, ao social, ao marco e permitiu que estes invadissem o universo privado num grau considerável. A cultura do consumo é mundana em grande parte; no entanto, esse mundanismo é onde vivemos e respiramos - e cada vez mais - pois sentimos que a esfera pública da vida tornou-se um espetáculo passível do consumo e que está sempre distante enquanto esfera de participação direta. Portanto, a "cultura de consumo" é uma história de luta pela alma da vida cotidiana, de batalhas para controlar a estrutura do cotidiano (SLATER, 2002, p.13).
}

Ao lidar com a mídia e com a cultura do consumo, nos debatemos e confrontamos nossos princípios, sobretudo ao perceber como nossas vidas estão sendo comercializadas por meio de estilos específicos de consumo. Para Slater (2002, p.14), "ao consumirmos, rotineiramente, construímos identidades e relações sociais a partir de recursos sociais com os quais nos envolvemos como agentes". Vivenciamos, desse modo, o efeito ilusório do livrearbítrio pessoal da aquisição de mercadorias quando, na verdade, somos parte de um "acordo social onde a relação entre a cultura vivida e os recursos sociais, entre modos de vida significativos e os recursos materiais simbólicos dos quais dependemos, são mediados pelos mercados", aponta o autor (SLATER, 2002, p.17). Para Rocha (2009, p.17), o consumo "fala incessantemente no sentido do estabelecimento do mercado como figura determinante, como passagem crucial na direção do capitalismo, atingindo inapelavelmente, o tecido social e a cultura".

A narrativa midiática - publicidade em especial - produz sentido para os bens de consumo e, nesse processo, prescreve valores e modela práticas sociais. O consumo, 
portanto, utiliza um complexo sistema de representações, que define capitais sociais, expressa identidades, projetos, comportamentos, subjetividades, diferenças, relações e oferece um mapa classificatório que regula várias esferas da experiência social na cultura contemporânea (ROCHA, 2009, p.17-18).

A partir desse trecho, percebemos de forma evidente a relação entre a comunicação midiática e a cultura do consumo. Para Rocha (2009, p.18), o consumo é "um código que tem na comunicação de massa sua instância de viabilização social - instância ampla, aberta e compartilhada" e as narrativas midiáticas, então, atuam como propagadoras desse código. "Dispositivos e tecnologias diversas - televisão, internet, publicidade (...) - interpretam a produção, socializam para o consumo e fornecem um sistema classificatório que permite ligar um bem de consumo a cada outro e todos juntos às nossas experiências de vida" (ROCHA, 2009, p.17). Consumimos, assim, mercadorias, significados, representações e espetáculos elaborados pela comunicação midiática e dissipados em nossas rotinas.

\section{Tecnologia e Entretenimento: imagens e afetos}

A partir da Revolução Científico-Tecnológica de 1870, as inovações tecnológicas adentraram e modificaram o cotidiano das pessoas, sobretudo na relação com o trabalho em virtude das demandas dos complexos industriais que se estabeleciam nas cidades, explica Sevcencko (2001, p.59). Com o transporte elétrico, grandes coletivos podem se locomover rapidamente e as pessoas acabam, em consequência do controle tecnológico, transformando seus comportamentos: "nessa sociedade altamente mecanizada, são os homens e as mulheres que devem se adaptar ao ritmo e à aceleração das máquinas, e não o contrário" (SEVCENKO, 2001, p.62).

A alteração no padrão de comportamento das pessoas imposta pela preeminência das máquinas, das engenharias de fluxos e do compasso acelerado do conjunto, como seria inevitável, acaba também provocando uma mudança no quadro de valores da sociedade. Afinal, agora os indivíduos não serão mais avaliados pelas suas qualidades mais pessoais ou pelas diferenças que tornam única a sua personalidade. Não há tempo nem espaço para isso, (...) a forma prática de identificar e conhecer os outros é a mais rápida e direta: pela maneira como se vestem, pelos objetos simbólicos que exibem, pelo modo e pelo tom com que falam, pelo seu jeito de se comportar (SEVCENKO, 2001, p.63-64). 
Dessa maneira, identificamos e distinguimos as pessoas por meio dos símbolos externos que elas ostentam como o vestuário e os objetos pessoais; a valorização das qualidades humanas cede espaço para o capital, pois para o autor, "as pessoas são aquilo que consomem" (ibidem, p.64). Juntamente com a inserção das tecnologias no dia-a-dia das pessoas e a reconfiguração da relação com o tempo e o espaço, a organização das cidades e seus fluxos remodela também a sensibilidade dos indivíduos: a supervalorização do olhar, a capacidade de captar o movimento, a percepção da dinamicidade culminam em um aguçamento de modo geral da visualidade (SEVCENKO, 2001, p.65).

Nesse momento, se sobressaem formas de entretenimento que exploram a "possibilidade de ampliar os horizontes da imaginação e de instigar as mentes", como o cinema a encantar o público com truques rápidos de edição e montagem e o parque de diversões a deslocar abruptamente os corpos e desestruturar a forma como se percebia o mundo a partir dos brinquedos, aponta Sevcenko (2001, p.66-70). As chamadas "emoções baratas", cujo objetivo era divertir o maior número de pessoas por um baixo custo, comprovavam o interesse popular pela imersão proporcionada pelos frutos do advento da eletricidade; o sucesso da montanha-russa, por exemplo, indicou o apreço pela emoção vertiginosa que, mais à frente, alavancaria o surgimento da indústria do entretenimento (ibidem, p.73).

\begin{abstract}
Mais que mera diversão ou entretenimento, o que essa indústria fornece, ao custo de alguns trocados, são porções rigorosamente quantificadas de fantasia, desejo e euforia, para criaturas cujas condições de vida as tornam carentes e sequiosas delas. Como disse outro teórico, Guy Debord ${ }^{2}$, essa indústria se esforça por compensar o extremo empobrecimento da vida social, cultural e emocional, arrebatando as pessoas para uma celebração permanente das mercadorias saudadas como imagens, como novidades, como objetos eróticos, como espetáculo, enfim. (SEVCENKO, 2001, p.81).
\end{abstract}

Nos dias de hoje, para Coelho e Pereira (2008), o entretenimento pode ser compreendido não apenas como uma indústria lucrativa, mas também como uma "linguagem global que emerge e se espraia por toda a cultura, como consequência direta, dentre outros fatores, da experiência de consumo dos produtos massivos de entretenimento". Para os autores, na contemporaneidade, abdica-se de definições anteriores que se referiam ao entretenimento como práticas realizadas em oposição aos horários de trabalho rigidamente

${ }^{2}$ DEBORD, Guy. The Society of Spectacle. Nova York: Zone Books, 1995. 
delimitados, como intervalos de lazer, tendo em vista que a sociedade atual já exigiria uma demanda pela linguagem do entretenimento como uma espécie de formato interessante e desejável para fluxos e trocas em variados segmentos (COELHO; PEREIRA, 2008).

O entretenimento seria consumido, dessa forma, por meio da aquisição de um "tecido", um revestimento lúdico que tornaria os conteúdos mais palatáveis.

\begin{abstract}
Devem agora se expressar na linguagem do entretenimento - como um imperativo os chefes com os seus subordinados, o ilustre palestrante diante do seu público de executivos, o professor com os seus alunos, o candidato político com o seu potencial eleitorado, o pai com os seus filhos, os amantes entre si, o anunciante aos seus consumidores, enfim, todos que buscam a boa comunicação. Assim, os discursos, as metodologias de ensino e de pesquisa, os ideais políticos, os valores éticos e os princípios morais, os sistemas de pensamento e os dogmas religiosos, as marcas, as empresas e seus produtos, todos, sem exceção, devem se apresentar envoltos no exuberante tecido do entretenimento. Todas as expressões, então, nos novos tempos, parecem ganhar um ar leve, ágil, lúdico, divertido, engraçado, colorido, multissensorial, para que possam ser reconhecidas, dignas de atenção e de valor (COELHO; PEREIRA, 2008).
\end{abstract}

Segundo Pereira (2013, p.11), as marcas e empresas perceberam que a demanda pelo entretenimento como uma expressão constante nas lógicas de comunicação e consumo representa não apenas o interesse em mercadorias de qualidade, mas também a imprescindibilidade de "informar e divertir, gerar experiências que ativem diferentes sentidos, de forma lúdica e alegre. Como se todos tivessem viciados e demandassem cada vez mais diversão e prazer".

Essa perspectiva sobre o entretenimento como uma linguagem que se fundiria a múltiplos conteúdos corrobora o raciocínio desenvolvido por Sevcenko (2001) ao denunciar o culto contemporâneo à visualidade e o consumo do espetáculo previamente defendido por Debord (1995). Para o autor, "não apenas consumimos imagens em massa todos os dias, mas também ajudamos a multiplicá-las", e isso se dá tanto involuntariamente quando somos filmados por diversos equipamentos de segurança, quanto voluntariamente ao registrarmos o mundo ao nosso redor em nossos dispositivos (SEVCENKO, 2001, p.124).

Em princípio não há nada de errado com essa multiplicação exacerbada de imagens. Ao contrário, como as possibilidades de produzi-las sempre foram um privilégio das elites e como a cultura dominante sempre as manteve restritas a rigorosos códigos de representação ou submetidas a rígidas classificações temáticas, estilísticas e técnicas, as possibilidades de sua multiplicação introduziram componentes democráticos, emancipadores e experimentais (SEVCENKO, 2001, p.125). 
As imagens possuem tão vasto potencial para "capturar os sentidos, o desejo e a atenção dos seres humanos, que logo os estrategistas as elegeram como o meio ideal para difundir ideias, comportamentos e mercadorias", destaca Sevcencko (2001, p.125). O consumo de imagens e a sua manipulação proporcionada pela popularização tecnológica, portanto, celebram o aspecto democrático da sociedade do espetáculo e do consumo. Por outro lado, as relações humanas são reconfiguradas diante da comunicação constantemente mediada por recursos tecnológicos: "é um mundo sem dúvida vistoso, mas não bonito; intenso, mas não agradável; potencializado por novas energias e recursos, mas cada vez mais carente de laços afetivos e de coesão social" (SEVCENKO, 2001, p.90).

Machado (2001, p.14) entende que na sociedade em que vivemos, permeada por aparelhos eletrônicos, circulam dois discursos antagônicos: ora as máquinas são vistas como próteses humanas que substituem atividades de criação e apontam a nossa impotência; ora atuam como companheiros atraentes e indispensáveis para o nosso desenvolvimento, objetos de desejo e fetiche. Para o autor, o consumo de imagens é tamanho que acabamos por confundir os fatos com a representação deles:

Essa é a lógica subjacente desta nossa sociedade permeada pelos aparelhos de "duplicação" do real, imersa num mar de signos audiovisuais que constituem para nós o atestado de realidade das coisas. Cada vez mais, nós tendemos a confundir o evento com a sua enunciação simbólica, ou melhor ainda, os próprios eventos não acontecem senão para sua circulação nos veículos de informação (MACHADO, 2001, p.236).

Ao nos relacionarmos com os aparelhos de enunciação audiovisual, supervalorizamos essas instâncias como se fossem verdadeiros totens a cristalizar nossa vida simbólica (MACHADO, 2001, p.238). Nossas redes de "circuitos virtuais" tendem a restringir nossas relações afetivas, cada vez mais exclusivas; "casais que se falam por meio de secretárias eletrônicas, pais que se comunicam com os filhos pela internet, professores que ensinam por teleconferência a alunos que respondem por e-mail", aponta Sevcenko (2001, p.92). Usufruímos as vantagens e os benefícios que surgem com a inserção da tecnologia em nosso cotidiano, mas ao "enquadrar" nossas vidas, nos sujeitamos também ao império imagético e aos complexos códigos e fluxos relacionais instaurados. 
No intuito de observar de que maneira a comunicação midiática se apropria dessa profusão de imagens, do culto ao consumo e da produção do espetáculo, analisaremos a seguir a campanha publicitária do smartphone iPhone 6s da marca Apple - intitulada "Só mudou uma coisa. Tudo" - visando evidenciar como são trabalhadas as questões aqui discutidas sobre a inserção do entretenimento e da tecnologia no dia-a-dia, bem como da sua interferência nas relações humanas. Primeiramente descreveremos as informações técnicas da campanha, e, em seguida, traçaremos as possíveis conexões entre o discurso publicitário apresentado e os argumentos teóricos aqui articulados.

\section{Campanha iPhone 6s Apple - "Só mudou uma coisa. Tudo"}

Lançada em novembro de 2015, a campanha "The only thing that's changed is everything"', assinada pela Media Arts Lab, da agência TBWA/Worldwide, logo chegou ao Brasil com três vídeos e também cartazes de rua em português. Os anúncios enfatizam, em tom irônico, que o novo aparelho trás poucas mudanças, quando na verdade afirma que o modo de interagir com o iPhone mudou completamente. Vamos descrever cada um deles.

No primeiro vídeo, o destaque é a divulgação do recurso da pressão do touch, ou seja, em diversas situações mostradas é possível aplicar um toque mais demorado com o dedo na tela do telefone otimizando e acelerando as funções do dispositivo. Zoom, alternância de telas, acionamento de comandos e outras tarefas podem ser executados com essa nova possibilidade de toque intenso na tela. Nessa versão, 6s, o consumidor poderá optar também pela cor "ouro rosa" no revestimento do celular.

Mais uma mudança é ativação por voz da "Siri", assistente virtual da Apple, que antes estava restrita ao acesso manual. E talvez a mais interessante aquisição dos usuários da marca com esse modelo seja a câmera. Gravando vídeos em $4 \mathrm{~K}$ - tecnologia que permite uma maior resolução das imagens - o aparelho pode ser usado para produção de filmes com qualidade profissional. A captura das famosas "selfies" também foi aprimorada com a inclusão de um flash frontal. E o próprio registro das fotos mudou, pois agora o celular grava alguns segundos de vídeo antes e depois do disparo de captura da imagem, produzindo pequenos filmes. Todos

3 Informações disponíveis em: <http://www.meioemensagem.com.br/home/comunicacao/2015/11/13/appledivulga-o-novo-iphone-6s-no-brasil.html $>$ e $<\underline{\text { http://ihelpbr.com/apple-divulga-mais-dois-comerciais-do-iphone- }}$ 6s-no-brasil/>. Acesso em: 10/07/2016. 
esses aperfeiçoamentos do aparelho, como indica a locução do anúncio, mudam o jeito como você faz as coisas.
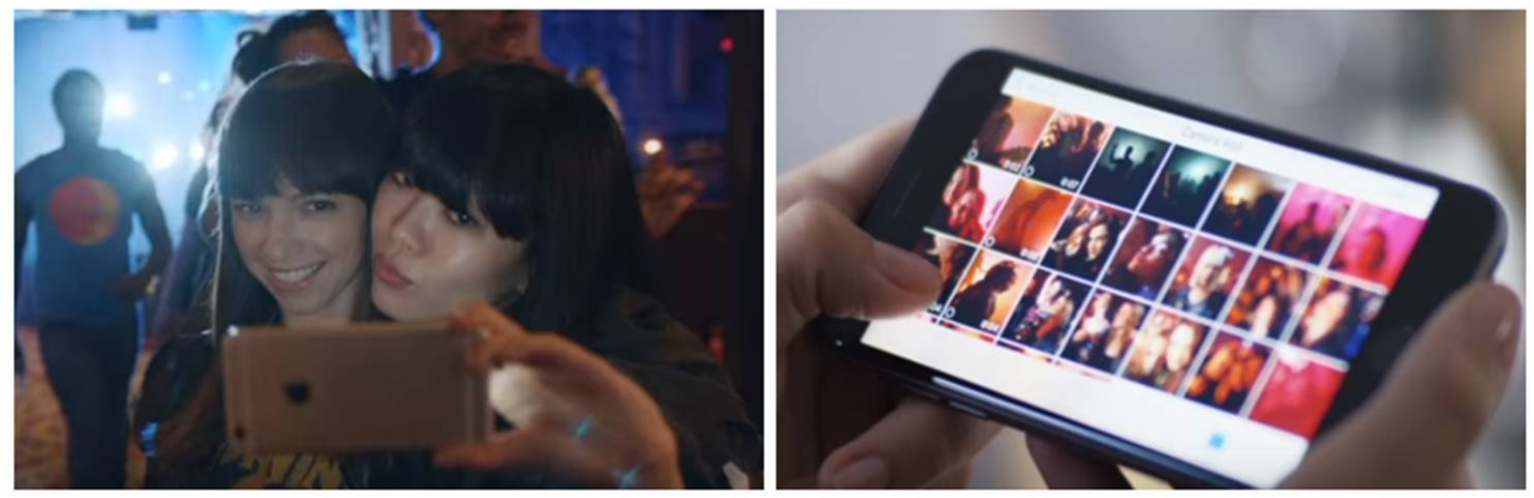

Figura 1 - Primeiro vídeo da campanha do iPhone 6s destacando o flash frontal ${ }^{4}$.

Figura 2 - Segundo vídeo da campanha do iPhone 6s destacando as funções do toque intenso na tela 5

No segundo vídeo, o uso do toque intenso na tela também surge como mote do anúncio e ao afirmar que "não mudou muita coisa", a locução pontua que "a sensação é diferente", explicando que "quase tudo que você faz parece diferente e foi isso que mudou". Um dos exemplos dados é a utilização da pressão do dedo na tela para abrir outras funções como quando recebemos um endereço em uma mensagem de e-mail e seguramos o toque nesse texto, o celular automaticamente abre o "Mapas", indicando a localização e o melhor trajeto para chegar ao destino. As ações atreladas a esse toque são variadas e o usuário deverá experimentar para aprender como usufruir das conexões criadas como espécies de "atalhos" para navegação.

O terceiro anúncio se utiliza das alterações na câmera para a construção do roteiro. $\mathrm{O}$ texto tem início com: "Esse é o iPhone 6s. Não mudou muita coisa na câmera, a não ser o jeito que você tira uma foto, acha uma coto, compartilha uma foto". Na sequência, divulga a possibilidade de gravar os pequenos vídeos juntamente com as fotos fazendo com que as próprias fotos mudem, pois "agora elas se mexem". Ao voltar a falar da câmera com tecnologia 4K, a locução explica que "você pode até filmar em câmera lenta e em HD $^{6 "}$.

\footnotetext{
${ }^{4}$ Disponível em: $<$ https://www.youtube.com/watch?v=wINni18fWNA>. Acesso em: 10/07/2016.

${ }^{5}$ Disponível em: <https://www.youtube.com/watch?v=b-XTUCWXinM>. Acesso em: 10/07/2016.

${ }^{6}$ HD é a sigla para high definition, que significa alta definição. 

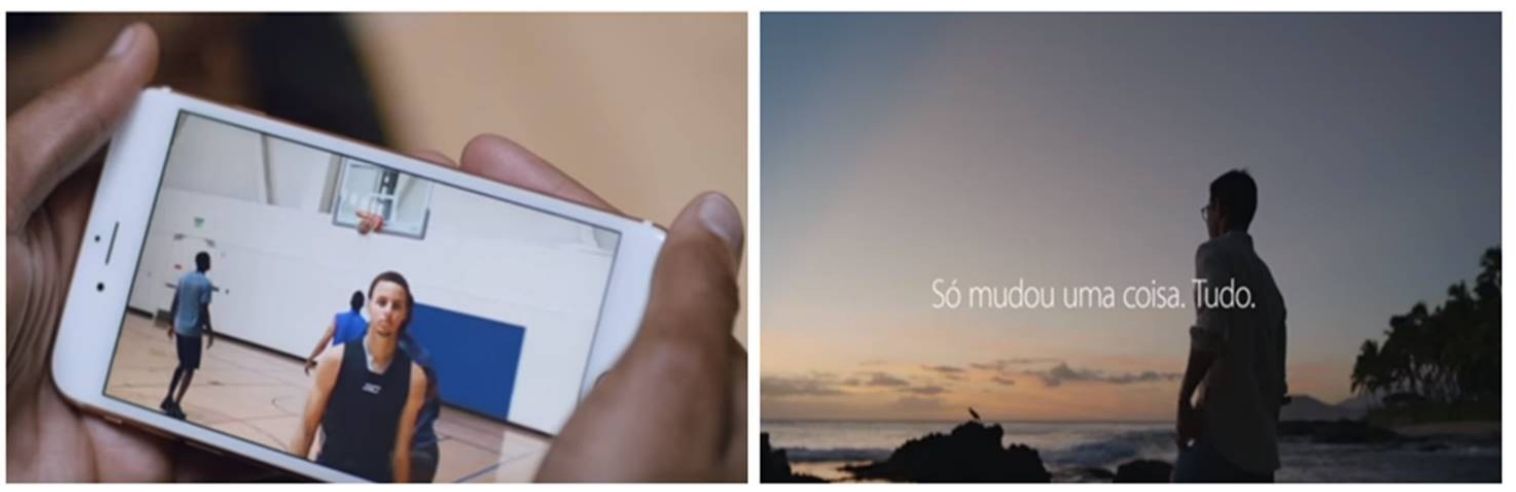

Figura 3 - Terceiro vídeo da campanha do iPhone 6s destacando a filmagem em câmera lenta ${ }^{7}$.

Figura 4 - Slogan da campanha no segundo vídeo divulgado.

Com a descrição dos três vídeos que compõem a campanha foi possível perceber o intuito da marca ao explorar ocasiões distintas do cotidiano dos usuários na interação com o aparelho enfatizando de que maneira as funcionalidades tinham sido aprimoradas pensando em uma navegação mais rápida e inteligente, construindo uma maior conexão entre os aplicativos e oferecendo maior qualidade nos dispositivos de entretenimento, sobretudo no que tange a captação, visualização e compartilhamento de imagens.

Após essa etapa descritiva e investigativa, retomamos os argumentos defendidos visando aprofundar a reflexão sobre as diferentes perspectivas dessas teorias que foram exploradas nos anúncios. Inicialmente, constatamos que a utilização do aparelho celular exerce tamanha influência na vida dos consumidores que a marca passa a se utilizar de pequenas brechas tecnológicas existentes para otimizar o "relacionamento" desses usuários com o dispositivo e todas as esferas da comunicação audiovisual ali embutidas. Como afirmou Sodré (2001, p.21), as instâncias da comunicação midiática se empenham em construir um espaço, um ambiente em que, de tão sólido, transforma os processos de representação em apresentação, em uma realidade. O anúncio, por sua vez, defende que os novos recursos tecnológicos do celular possibilitam não só uma melhor "condensação" do mundo em registros imagéticos de qualidade como a própria gestão e propagação desses conteúdos por intermédio de atalhos com as redes sociais digitais.

Ainda se apoiando no pensamento de Sodré (2006, p.12), estabelecemos, a partir dessa pesquisa, a conexão entre as melhorias do iPhone 6s e a reconfiguração de nossas vidas em

\footnotetext{
${ }^{7}$ Disponível em: <https://www.youtube.com/watch?v=FT9fd2YfWmw>. Acesso em: 10/07/2016. 
um verdadeiro espetáculo. A valorização da qualidade técnica da câmera que produzirá vídeos em alta definição e que, com os filmes produzidos juntamente com as fotos, tenciona até a compreensão dos formatos "vídeo" e "foto", revela o atual culto às sensações, ao prazer associado ao entretenimento audiovisual e o enaltecimento do consumo estético.

Diante da campanha publicitária, destacamos o discurso "pedagógico" da Apple ao informar de maneira didática para que serve e como funcionam cada uma das novidades do aparelho. Como apontou Rocha (2009, p.18), as narrativas midiáticas, principalmente as publicitárias, agregam sentido aos bens de consumo promovendo ligações entre os objetos e os momentos de nosso cotidiano. O iPhone $6 \mathrm{~s}$, nesse caso, não é exibido como um equipamento de qualidade para conectar pessoas apenas, mas como um produto capaz de mudar a forma como executamos quase todas as tarefas e, como afirma a locução, capaz de propiciar uma experiência estética diferenciada, com uma "sensação diferente".

A expressão da linguagem do entretenimento, proposta por Coelho e Pereira (2008), está imbrincada ao texto publicitário da marca e, concomitantemente, à compreensão do uso do aparelho como um dispositivo de comunicação e também de lazer. A ênfase dada à facilidade e rapidez da navegação, bem como à ludicidade da realização de cada tarefa indicam o intenso entrelaçamento entre tecnologia e entretenimento, independentemente da atividade a ser executada. A forma de fazer, a proposta de uma interação leve, fácil, divertida e, progressivamente, multissensorial - a exemplo da ativação por voz da assistente "Siri" reiteram a demanda contemporânea por lazer.

Percebemos, de modo mais implícito, o reconhecimento das enunciações simbólicas em detrimento da realidade, ou seja, em função dos dispositivos eletrônicos e das ambiências midiáticas construídas, vivenciamos a "duplicação" do real a partir dos materiais audiovisuais que consumimos diariamente. Ao encarecer o compartilhamento de vídeos e o fortalecimento, bem como a alimentação, dos ambientes virtuais, os anúncios reforçam nossa sujeição aos contratos sociais e nossa convivência com o espetáculo e a simulação. Como ressaltou Machado (2001, p.238), na sociedade do império da imagem e das máquinas, vangloriamos nossa vida simbólica.

\section{Considerações Finais}


Após percorrer o trajeto teórico e analisar os vídeos da campanha selecionada, podemos agrupar algumas questões que vieram à tona e permanecem carentes de reflexão e aprofundamento investigativo:

1) O culto ao espetáculo faz parte de nosso cotidiano. Já nem mais nos damos conta. Naturalizamos a produção e o consumo de uma realidade "virtual". O bios midiático (SODRÉ, 2006, p.102) que estamos imersos passa a nos reger e, simultaneamente, trabalhamos para a sua manutenção; somos atores e servos desse fluxo estético-comunicativo;

2) A tecnologia altera o comportamento das pessoas. Assim como naturalizamos o espetáculo, inserimos os equipamentos eletrônicos em nossa rotina de modo fluido. Adaptamo-nos às máquinas e à freneticidade imposta por elas (SEVCENKO, 2001, p.62). Trazendo vantagens e desvantagens, convivemos com as tecnologias. Afastando-nos ou nos aproximando das pessoas e do mundo, consumimos as máquinas tanto quanto elas nos consomem;

3) O entretenimento se espraiou em nossas práticas de consumo. Figurando como linguagem como defendem Coelho e Pereira (2008) ou como força de negócio imprescindível (PEREIRA, 2013, p.11), a demanda pela ludicidade é real e está sendo fartamente atendida; estamos, assim, "viciados" em prazer.

Diante desses apontamentos, refletimos sobre a nossa relação com a comunicação midiática, com a produção e o consumo do espetáculo e com a interferência das tecnologias com o smartphone, de modo mais específico - em nossas vidas. Com a análise dos anúncios, visualizamos de modo prático de que forma essas apropriações midiáticas acontecem e são trabalhadas no discurso publicitário. Concluímos, ainda que prematuramente, que será necessário, de modo incessante, conceder maior atenção aos processos de hibridação que atrelam comunicação, entretenimento e tecnologia. Sendo áreas férteis e de permanente expansão e transformação, acreditamos que muitos conceitos já estabelecidos serão questionados e até mesmo quebrados com o passar do tempo. Ansiamos por continuar essa investigação, ávidos por compreender de que forma atuamos, e também nos sujeitamos, no cenário contemporâneo. 


\section{Referências}

COELHO, J.; PEREIRA, V. A. Porque o entretenimento deverá ser objeto de estudo e de ensino nas escolas de comunicação e negócios. Disponível em: $<\mathrm{http}: / \mathrm{goo} . \mathrm{gl} / \mathrm{zcMzNu}>$. Acesso em: 07/01/2016.

MACHADO, Arlindo. Máquina e Imaginário. São Paulo, Edusp, 2001.

MILLER, Daniel. Consumo como cultura material. Horizontes Antropológicos. Porto Alegre, ano 13, n.28, p.33-63, jul/dez, 2007.

PEREIRA, V. A. Entretenimento como linguagem e multissensorialidade na comunicação contemporânea. Trabalho apresentado no XXXVI Congresso Brasileiro de Ciências da Comunicação. Manaus, setembro de 2013.

ROCHA, E. Invisibilidade e revelação: camadas populares, cultura e práticas de consumo apresentação. IN: ROCHA, A; SILVA, J (Orgs.) Consumo na base da pirâmide: estudos brasileiros. Rio de Janeiro: Mauad X, 2009, p.13-18.

SEVCENKO, N. A corrida para o século XXI: no loop da montanha-russa. São Paulo: Companhia das Letras, 2001.

SLATER, D. Cultura do consumo \& modernidade. São Paulo: Nobel, 2002.

SODRÉ, M. As estratégias sensíveis: afeto, mídia e política. Petrópolis, RJ: Vozes, 2006.

A televisão é uma forma de vida. FAMECOS, Porto Alegre, n.16, p.18-35, 2001. Disponível em: <http://goo.gl/Wfiuxe>. Acesso em: 06/07/2016. 